\title{
MUSIK BECANANG DALAM MALAM ADAT BEGURU PADA MASYARAKAT GAYO KECAMATAN BEBESEN, KABUPATEN ACEH TENGAH \\ (Kajian terhadap bentuk penyajian dan bentuk musik)
}

\author{
Dara Arigustika.AZ \\ Prodi Pendidikan Musik
}

\begin{abstract}
Dara Arigustika.AZ. NIM 2113340013. Becanang Traditional Music In The Evening Beguru in Gayo Society Bebesen Districts, District Central Aceh (Study of the form of presentation and form of music). Faculty Of Language and Art. Medan State University, 2015.This research is a study about the existence of the forms of presentation becanang music and music form becanang the Gayo people in the District of Central Aceh District Bebesen. The purpose of this study was to determine the presence of music in the district becanang Bebesen, form of presentation and form of music in the evening becanang beguru indigenous community in the district of Gayo Bebesen, District Central Aceh.This research is based on theoretical foundation to explain the meaning of existence, understanding forms of presentation, understanding forms of music, understanding night becanang indigenous communities beguru Gayo. The method in this study used a qualitative descriptive method. The sample in this study is penatuah customary understanding of the cultural traditions of indigenous communities which are also Gayo Gayo people of Central Aceh district. This data collection is done by the method of observation, interviews, laboratory work and literature study. This study was taken at the site of the District Bebesen, Central Aceh district and the research was conducted from June 2015 through to August 2015. The results showed that the presence in the district Bebesen becanang music still plays an important role in any wedding procession indigenous Gayo people which can be seen from its function, especially in the traditional evening event Beguru to be a communication tool and as a sign that Beguru event to begin. Form of presentation of music becanang played with several musical instruments tradition and consists of Gegedem, cymbals, Memong and gong, music becanang has a very important role in every stage of the traditional events marriage Gayo society, especially on the eve of indigenous Beguru as a communication tool caller local communities and as a sign that the traditional evening Beguru begin. Becanang musical form only play three different forms of rhythm alone, three rhythm is played in alternating turns, the most prominent bring rhythm motif is gegedem, on Memong instruments, cymbals and gongs just follow it, cymbals used as a regulator of tempo.
\end{abstract}

Keywords: Forms of presentation, the form of music, music becanang 


\section{PENDAHULUAN}

Suku Gayo adalah suku yang

hidup dan berkembang di Provinsi

Aceh. Kebudayaan Gayo sangat

beragam mulai dari tarian, musik , dan teater. Kebudayaan dari tiap suku bangsa memiliki keunikan dan kekayaan tradisi masing-masing dimana didalamnya juga terkandung nilai-nilai luhur untuk kemuliaan hidup. Tak terkecuali kebudayaan masyarakat Gayo yang berada di sekitar kawasan Takengon Aceh Tengah (Gayo Lut) pada saat mempersiapkan hajatan besar seperti upacara perkawinan harus melewati beberapa tahapan adat, yang setiap tahapannya tersimpan makna yang sakral untuk kebahagiaan hidup rumah tangga pasangan pengantin.

$$
\text { Beguru yaitu acara yang }
$$

diadakan sesudah acara malam

begenap yaitu pada pagi hari sesudah sholat subuh. Beguru artinya belajar, yang merupakan prosesi pemberian nasihat kepada calon pengantin dan biasanya disertai dengan pepongoten (tangisan) sambil sungkeman kepada orang-orang tua calon pengantin, calon pengantin akan diberi berbagai nasihat dan petunjuk tentang bagaimana nantinya mereka bersikap dan berperilaku dalam membina rumah tangga, sebelum acara beguru dimulai orang-orang tua akan becanang (bermain canang) di tempat acara tersebut sambil menunggu tamu-tamu datang begitu juga setelah acara beguru selesai.

Salah satu prosesi upacara perkawinan masyarakat Gayo yang paling digemari orang-orang tua lanjut usia adalah becanang (bermain canang) pada saat beguru. Becanang merupakan sebutan untuk sekelompok permainan musik 
perkusi, alat musik yang di pakai dalam musik becanang ini antara lain canang, memong, gong dan gegedem.

Becanang adalah salah satu permainan musik tradisi khas Gayo yang sangat dilestarikan hingga saat ini. Setiap prosesi adat dalam acara penikahan pada masyarakat suku Gayo selalu menggunakan musik becanang, musik becanang ini juga berfungsi sebagai alat komunikasi untuk memanggil masyarakat setempat agar hadir di acara beguru yang diselenggarakan.

Musik becanang ini dimainkan dengan ritem yang khas seperti ritem cincah nangka, canang selalu dan ritem redep, Ritem cincah nangka adalah ritem yang sudah mulai di kembangkan, ritem ini merupakan ritem yang terdengar sangat ceria, menurut ceritanya ritem ini timbul ketika para petani di tanah Gayo berhasil panen hasi kebunnya dengan hasil yang sangat memuaskan, $\quad$ ritem ini menggambarkan kesenangan mereka saat mereka merasakan bahagia karena hasil panenannya, ritem canang selalu adalah ritem yang terdengar sangat monoton dan dimainkan tidak memakai gegedem sedangkan ritem redep adalah ritem yang terdengar seperti staccato, ritem ini menggambarkan ketegasan dari masyarakat Gayo

\section{Di Kecamatan Bebesen} memiliki banyak perkampungan, pada zaman dahulu disemua perkampungan selalu memainkan musik becanang apa bila ada salah satu warga yang menyelenggarakan acara beguru, becanang ini menjadi suatu kewajiban di dalam prosesi adat 
Beguru (memberi nasihat)

menjelang akad pernikahan, akan tetapi karena kehidupan sudah semakin modern dan adanya pengaruh kebudayaan luar masyarakat suku Gayo mulai meninggalkan kebiasaan becanang ini, sekarang becanang seperti tidak lagi menjadi kewajiban di beberapa perkampungan khususnya bebesen, sebagian dari mereka mulai tidak lagi menggunakan musik becanang apabila ada acara beguru yang diselenggarakan. Adapun judul penelitian ini adalah "Musik Becanang Dalam Malam Adat Beguru Pada Masyarakat Gayo Kecamatan Bebesen, Kabupaten Aceh Tengah (kajian terhadap bentuk penyajian dan bentuk musik)" untuk dideskripsikan dalam bentuk karya ilmiah yang dikemas dalam bentuk skripsi.
Menurut Al.Sukohardi dalam bukunya Teori Musik Umum (2012:5) :
"Nada adalah bunyi yang teratur, artinya mempunyai bilangan getar (frekuensi) yang tertentu. Tinggi rendahnya bunyi (suara) bergantung pada besar kecilnya frekuensi tersebut. Dalam musik, tinggi rendah dan panjang pendeknya nada dapat ditunjukan dengan tanda yang di sebut : titinada atau not." Menurut Budilinggono dalam bukunya Bentuk dan Analisa Musik (1993:1) :
"Musik adalah perwujudan ide-ide atau emosi, pengertin tersebut akan 


\begin{tabular}{|c|c|}
\hline mengandung konsekuensi & Pengertian penyajian berasal dari \\
\hline bahwa musik sebenarnya & kata "saji" yaitu mempersembahkan, \\
\hline mempunyai makna. Bentuk & sedangkan penyajian itu sendiri \\
\hline musik juga mengalami & mengandung pengeertian proses, \\
\hline proses gramatika,proses ini & cara dan perbuatan yang telah \\
\hline tetap di dukung oleh uatu & tersedia untuk dinikmati. Bentuk \\
\hline keterampilan dalam & penyajian dalam musik adalah suatu \\
\hline menuangkan suatiu ide. & susunan atau wujud penyajian \\
\hline Bentuk dan analisis musik & secara utuh. Menurut Djelantik \\
\hline akan sangat memuaskan & bukunya \\
\hline apabila telah didasari oleh & Kebudayaan (1999:73) : \\
\hline penguasaan mengenai teori & “penyajian \\
\hline musik, harmoni dan ilmu & bagaimana kesenian itu \\
\hline musik lain yang dapat & disungguhkan \\
\hline dipergunakan sebagai & yang menyaksikannya, \\
\hline pendukung di dalam proses & penonton, para pengamat, \\
\hline pemikiran analisis secara & pendengar, \\
\hline menyeluruh." & khalayak ramai pada \\
\hline penyajian & umumnya, \\
\hline representatif lebih cenderung ke & unsur yang berperan \\
\hline realisme, & dalam penampilan atau \\
\hline manifestatif tidak mengungkap & penyajian adalah bakat, \\
\hline masalah secara langsung". & \\
\hline
\end{tabular}


keterampilan, serta sarana

dan media."

Musik becanang adalah sebutan untuk sekelompok permainan musik perkusi, alat musik yang dipakai dalam musik becanang ini antara lain adalah canang, memong, gong dan gegedem. Musik becanang adalah musik tradisi khas Gayo yang dimainkan dengan cara menabuh canang secara bersamasama dengan ritem yang berbeda. Musik becanang biasa dimainkan oleh kaum ibu-ibu separuh baya dan musik becanang ini selalu dimainkan dalam adat malam beguru dalam tradisi perkawinan adat Gayo.

Malam adat beguru selalu disertai sungkeman kepada kedua orang tua untuk memohon do'a dan restu. Di dalam malam adat beguru calon pengantin akan diberi siraman rohani dan nasihat-nasihat sebelum membina rumah tangga nanti. Malam adat beguru adalah tradisi perkawinan adat Gayo yang harus dilakukan sebelum menjalani akad pernikahan.

\section{Lokasi dan Waktu Penelitian}

Lokasi penelitian yang dipilih untuk mengadakan penelitian ini yaitu di Kecamatan Bebesen, Kabupaten Aceh tengah.

\section{Populasi dan Sampel Peneltian}

\section{Populasi}

Populasi adalah wilayah generalisasi yang terdiri atas: obyek/subjek yang mempunyai kualitas dan karakteristik tertentu yang ditetapkan oleh peneliti untuk dipelajari dan kemudian ditarik kesimpulannya. Jadi populasi bukan hanya orang, tetapi juga objek dan benda-benda alam yang lain. Populasi juga bukan sekedar jumlah yang ada pada objek/subyek yang dipelajari tetapi meliputi seluruh karakteristik/sifat yang dimiliki oleh subyek atau obyek itu" (Sugiono,2009:117).

Berdasarkan pendapat diatas, maka populasi yang digunakan 
bersifat terbatas. Maka populasi yang digunakan dalam penelitian ini adalah musik becanang, file video rekaman dan tokoh adat/penatuah yang telah banyak mengetahui tentang adat dan kebudayaan masyarakat Gayo, khususnya proses malam adat beguru yang ada di kampung Bebesen. Hal ini dilakukan agar dalam pengumpulan data-data diperoleh data-data yang valid.

\section{Sampel}

Banyak penelitian yang dilakukan pada sampel, yaitu sebagaian dari kelompok unsur yang lebih luas atau populasi. Sampel harus benar-benar mewakili populasi, bukan dipilih semata-mata karena kemudahannya (Sproull dalam Dubagyo, 2001:225).

Berdasarkan pendapat di atas maka dapat peneliti mengambil sampel penelitian antara lain file video rekaman dari musik becanang dan sebagian dari populasi yaitu 3 orang penatuah adat.

Teknik Pengumpulan Data

Teknik pengumpulan data yang dilakukan adalah sebagai berikut:

1. Studi Kepustakaan

2. Observasi dan Pengamatan

3. Wawancara

4. Kerja Laboraturium

5. Dokumentasi

\section{Teknik Analisis Data}

Teknik pengumpulan data merupakan langkah yang paling strategis dalam penelitian, karena tujuan penelitian adalah mendapatkan data. Tanpa mengetahui teknik pengumpulan data, maka peneliti tidak akan mendapatkan data yang memenuhi standart data yang ditetapkan (Sugiyono 2008:224)

Pada tahapan pengumpulan data, juga dilakukan analisis data untuk menemukan data-data yang lebih baik. Analisis selama pengumpulan 
data member kesempatan pada peneliti lapangan untuk kembali memikirkan tentang data yang ada dan menyusun strategi guna mengumpulkan data yang sering kali kualitasnya lebih baik (Miles, 2005:73). Hal ini dapat menjadi suatu koreksi bagi hal terselubung yang tidak terlihat sebelumnya dan membuat analisa sebagai usaha yang terus brrjalan dalam kaitannya dengan pengaruh di lapangan.

ISI

\section{A. Letak Geografis Kecamatan}

\section{Bebesen}

Kecamatan

Bebesen

merupakan salah satu kecamatan

berada di Kabupaten Aceh Tengah.

Sampai saat ini penduduk yang bermukim di Kecamatan Bebesen berjumlah 36.135 jiwa dengan potensi penghasilan penduduk hampir $80 \%$ dari pertanian. Masyarakat Gayo di Kecamatan Bebesen ini masih menjunjung tinggi nilai-nilai budaya yang ditinggalkan oleh para leluhurnya. Beguru merupakan salah satu persyaratan wajib yang harus dilakukan sebelum melangsungkan pernikahan atau ijab kabul pada masyarakat Gayo, ini merupakan persyaratan yang menjadi kelengkapan hidup untuk mengikat hubungan sosial dalam adat istiadat masyarakat Gayo.

B. Keberadaan Musik Becanang Dalam Adat Malam Beguru Pada Masyarakat Gayo, Kecamatan Bebesen,

\section{Kabupaten Aceh Tengah}

Musik becanang zaman dahulu hanya memiliki 3 instrumen saja yaitu canang, gong dan repana (gegedem), Dalam setiap prosesi upacara tersebut musik becanang 
sangat berperan penting untuk

menghidupan suasana dan menjadi

alat komunikasi untuk memanggil

masyarakat setempat agar hadir

diacara yang diselenggarakan kecuali

pada prosesi adat pernikahan risik

kono (perkenalan keluarga),

Munginte (meminang atau melamar)

turun caram (mengantar uang),

segenap dan begenap (musyawaarah

keluarga) prosesi ini tidak

menggunakan musik becanang.

C. Bentuk Penyajian Adat

Malam Beguru Pada

Masyarakat Gayo, Kecamatan

Bebesen, Kabupaten Aceh

Tengah

Tahapan-tahapan upacara

adat perkawinan yang selalu

diadakan sebagai berikut:

1. Nyerahen (Menyerahan kekas dan penerimaan ampang)

2. jege uce (pesta kecil)
3. Jege Kul

4. Beguru

5. Neik Bei

Keempat prosesi diatas dilaksanakan baik dirumah calon pengantin pria maupun dirumah calon pengantin wanita dengan seluruh keluarga besar masingmasing dan beberapa undangan terutama dari pihak ralik (laki-laki). Hari keempat merupakan hari dilaksanakannya akad nikah dimana berkumul keluarga besar dari kedua belah pihak dengan membawa calon pengantin pria ke rumah calon pengantin wanita.

Nyerahan artinya disinilah dengan secara resmi, yang mewakili kerabat kepada sukut di tempat beru (wanita), begitu juga berlaku ditempat pria untung meminta bantuan seluruh saudara. 
Musik becanang ini

dimainkan di dalam prosesi malam adat beguru, musik becanang ini tidak memerlukan sound system karena dimainkan di dalam ruangan yang bergema karena itu suara musik ini sudah terdengar keras, ruangan yang digunakan selalu dipilih ruangan yang besar dan kosong. Musik ini juga disajikan untuk para ibu-ibu rewangan (pemasak) yang sedang berada di dapur.

Musik becanang juga dimainkan oleh ibu-ibu separuh baya, di dalam musik becanang ini sering kali terlihat ibu-ibu yang berdiri dan menari karena terbawa suasana musik ini. Musik ini mampu memanggil jiwa-jiwa seni masyarakat Gayo, mereka melakukan tarian dengan berhadaphadapan seperti sedang melakukan komunikasi.

\section{Bentuk Musik Becanang}

Musik becanang memiliki bermacam-macam bentuk ritem variasi diantaranya ritem canang selalu, cincang nangka, dan redep, ketiga ritem ini dimainan secara bergantian dan berulang-ulang ritem inilah yang menjadi pokok dalam musik becanang.

\section{a.Canang selalu}

Canang selalu memiliki ritem yang sangat monoton, ritem ini paling sering dimainkan di dalam musik becanang, dalam ritem ini canang dan memong diminkan secara bergantian (sahut-sahutan) dengan tempo yang teratur, ritem ini menggunakan birama 4/4, gong selalu dimainkan pada akhir setiap birama.

\section{b.Cincang nangka}

Cincang nangka merupakan ritem yang terdengar riang, ritem 
yang dimainkan cepat dan terdengat

seperti ritem yang gantung, ritem ini

sering di mainkan di musik becanang dan sering juga dijadikan sebagai ritem iringan tari. Dalam musik becanang ritem ini mampu membawa pendengar untuk berdiri dan menari apalagi orang-orang yang berjiwa seni.

\section{c.Redep}

Redep adalah ritem yang terdengan seperti staccato, ritem ini menggambarkan ketegasan dari masyarakat Gayo. Ritem ini memiliki dua motif pada bar pertama dan kedua, frase pada ritem ini terdapat pada dua bar sekali contohnya dari bar 1 sampai dengan 2 dan kalimat pada ritem ini terdapat pada bar 1 sampai dengan 4 , ritem ini dimainkan secara berulang-ulang. Ketiga ritem inilah yang dimainkan secara berulang-ulang, ritem yang paling sering dimainkan dalam musik becanang yaitu ritem cincang nagka, karena dari ketiga ritem tersebut ritem yang paling terdengar sangat ceria adalah ritem cincang nangka. Contoh musik becanang jika di buat secara tertulis dalam partitur.

\section{KESIMPULAN}

Dari uraian-uraian tentang permasalahan dan pembahasan yang telah ditemukan pada bab-bab sebelumnya, maka pada bab ini penulis mencoba membuat kesimpulan mengenaqi bentuk dan penyajian musik becanang dalam malam adat beguru di Kecamatan Bebesen kabupaten Aceh Tengah sebagai berikut :

1. Keberadaan musik becanang masih berperan penting dalam proesi upacara adat pernikahan masyarakat Gayo di 
Kecamatan

Bebesen

Kabupaten Aceh Tengah

terutama pada malam adat

beguru. Malam adat beguru ini

merupakan salah satu prosesi

pernikahan masyarakat Gayo

yang sangat penting, setiap

masyarakat Gayo yang hendak

melangsungkan pernikahan

haruslah mengadakan malam

adat beguru. Didalam malam

adat beguru calon mempelai

akan diberi nasihat-nasihat

penting dalam menjalani

rumah tangga kelak.

2. Bentuk penyajian musik

becanang merupakan salah

satu bagian dari musik tradisi

Gayo yang sangat berperan

penting terutama pada prosesi

upacara perkawinan

masyarakat Gayo Kecamatan

Bebesen, Kabupaten Aceh
Tengah. Musik becanang harus

wajib dibunyikan disetiap

tempat yang akan

melangsungkan pernikahan di

Kecamatan Bebesen, apabila

musik becanang tidak

dipersiapkan maka

kemungkinan besar pernikahan

juga tidak akan dilaksanakan

sampai musik becanang

tersebut dipersiapkan dan

untuk dibunyikan kebiasaan ini

berlaku di kecamatan Bebesen

kabupaten Aceh Tengah.

3. Bentuk musik becanang yang selalu dimainkan dalam prosesi upacara pernikahan masyarakat gayo ini memiliki beberapa ritem khusus yaitu ritem canang selalu, ritem redep dan ritem cincang nangka,ritemritem inilah yang dimainkan secara berulang-ulang. 
Saran

Setelah melakukan penelitian

mengenai "Musik Becanang Dalam

Adat Malam Beguru Pada

Masyarakat Gayo Kecamatan

Bebesen, Kabupaten Aceh Tengah"

maka muncullah beberapa saran

sebagai upaya pengembangan musik

becanang sebagai berikut:

1. Kepada seluruh laisan masyarakat Gayo terutama generasi penerus jangan pernah melupakan alat-alat musik tradisional. Ketika kita mempunyai waktu dan kesepatan kita juga harus berusaha mempelajari cara memainkan alat musik tradisi Gayo tersebut. Khususnya untuk kaum wanita generasi Gayo supaya tetap menjaga dan mempelajari berbagai acara adat pada masyarakat Gayo terutama pada prosesi upacara adat perkawinan masyarakat gayo.

2. Dalam pembahasan ini peneliti sangat sulit untuk mendapatkan buku tentang masyarakat Gayo sebagai bahan referensi terutama tentang upacara adat perkawinan masyarakat Gayo, oleh karena itu diharapkan kepada petuah adat (orang yang mahir dan mengerti tentang adat-istiadat etnis Gayo ) untuk menuangkan ilmunya tentang adat-istiadat etnis Gayo ke dalam tulisan, agar tidak punah begitu saja seiring dengan berjalannya waktu.

\section{DAFTAR PUSTAKA}

Al.Sukohardi. 2012. "Teori musik Umum". Yogyakarta

Banoe,Pono. 2003. "kamus musik". Yogyakarta : Balai Pustaka 
Budilinggono. 1993. "Bentuk dan Analisa Musik”. Jakarta

C.Snouck Hurgronje.1996. “GAYO

(Masyarakan dan Kebudayaannya Awal Abad ke-20)". Jakarta : Balai Pustaka

Dandy sugono.2008. "Teori Singkat Penyajian Musik".Jakarta

Endaswara,Suwardi.2006,

"Penelitian

Kebudayaan".

Yogyakarta : Pustaka

Widyatama

Hadeli. 2006. "Metode Penelitian Kebudayaan". Jakarta : Bumi Pustaka

Karl Edmud prier Sj. "Ilmu Bentuk Musik".Yogyakarta : Pusat Musik Liturgi

Maryeani. 2005. "Metode Penelitian Kebudayaan”. Jakarta : Bumi Pustaka

Miles. 2005. "Metode penelitian Kebudayaan" . Jakarta : Bumi Pustaka
Miller. 2002. "The Role Of Music In the Life" : Quantum teaching

Sugiono. 2009. "Metode Penelitian Pendidikan Pendekatan Kuantitatif kualitatif dan $R \& B$ ”. Bandung : Alfabeta. 